\title{
Artelogie
}

Recherche sur les arts, le patrimoine et la littérature de l'Amérique latine

$4 \mid 2013$

Fêtes et célébrations en Amérique latine

\section{Samba de Roda : comemorando identidades afro- brasileiras através da performance musical}

\author{
Nina Graeff
}

\section{OpenEdition}

Journals

Edição electrónica

URL: https://journals.openedition.org/artelogie/6352

DOI: $10.4000 /$ artelogie.6352

ISSN: 2115-6395

\section{Editora}

Association ESCAL

\section{Refêrencia eletrónica}

Nina Graeff, «Samba de Roda : comemorando identidades afro-brasileiras através da performance musical», Artelogie [Online], 4 | 2013, posto online no dia 02 fevereiro 2013, consultado o 01 dezembro 2021. URL: http://journals.openedition.org/artelogie/6352 ; DOI: https://doi.org/10.4000/artelogie. 6352

Este documento foi criado de forma automática no dia 1 dezembro 2021.

Association ESCAL 


\title{
Samba de Roda : comemorando identidades afro-brasileiras através da performance musical
}

\author{
Nina Graeff
}

\section{Introdução}

O Samba de Roda do Recôncavo da Bahia, surgido em uma das regiões do Brasil de maior fluxo de escravos africanos, é provavelmente o mais antigo estilo de samba, ocorrendo até hoje em contextos tradicionais. Considera-se que tenha sido levado por migrantes baianos ao Rio de Janeiro em meados do século XIX, dando origem ao samba carioca conhecido mundialmente. Por sua importância histórica, o Samba de Roda foi a primeira prática musical brasileira a ser registrada como patrimônio cultural imaterial pela UNESCO, em 2005.Mas antes de ter importância histórica, o Samba de Roda cumpre um papel fundamental nas comunidades do Recôncavo. Samba, palavra que designa o evento, a dança, a letra, a música e o conjunto musical que a executa, é referido na região como uma entidade substancial - samba é "sangue", é "vida", é "alegria de viver", entre outros ditos. Assim, a festa não representa mero divertimento, mas sim elemento integrante e integrador de rituais tanto religiosos como seculares e, sobretudo, do cotidiano. Nesse contexto, Oliveira Pinto identificou o Samba de Roda ainda como elo entre as principais tradições do Recôncavo da Bahia : o candomblé, a capoeira e o maculelê (PINTO, 1991).

2 Uma roda de samba pode ter data e ocasião marcada dentro de um processo ritual longo, como na Festa da Boa Morte de Cachoeira, recebendo denominações específicas de acordo com o evento em questão. O samba executado no âmbito das celebrações a São Cosme e Damião, chamadas festas de caruru, é designado samba de caruru, por exemplo. A roda pode, no entanto, se desenvolver também espontânea e informalmente a qualquer momento e em qualquer local - geralmente na sala de uma casa particular acompanhada de canto e palmas. 
3 No momento em que o samba não está circunscrito em nenhuma celebração maior, mesmo quando espontâneo e imprevisto, deixa ele de ser uma comemoração ? Na inexistência de personagens, datas, ocasiões específicas e evidentes a serem celebradas, o que se estaria comemorando? Para refletir sobre essas questões, é necessário primeiramente compreender melhor quais aspectos e símbolos o rito do Samba de Roda comunica. Este não dispõe de mitos narrados, incorporados materialmente em fantasias ou insígnias que permitam a identificação direta de seus significados. Seus principais aspectos encontram-se na própria performance, dentro da roda : na música, na poesia $\mathrm{e}$ na dança. A análise desses três planos poderá indicar os símbolos transmitidos através dessa tradição secular.

4 Pesquisa etnográfica na região e uma intensa análise de documentação audiovisual atual e passada ${ }^{1}$ permitiram o reconhecimento de características constantes do Samba de Roda e das diferenças entre seus principais estilos - Samba Corrido, Samba Chula e Samba de Barravento - em diversos níveis: coreográfico, poético, tímbrico (instrumentos e estilo vocal), melódico e harmônico, bem como rítmico. Uma vez identificados, fez-se possível determinar transformações recentes na prática musical (cf. GRAEFF, 2012) e reencontra-los descritos sob outras denominações por Oneyda Alvarenga, Mário de Andrade, Sílvio Romero, entre outros. Dessa maneira, dados da performance essencialmente imateriais tornam-se marcas de historicidade (POMIAN, 1999), a serem verificadas e interpretadas na restituição de seu passado.

5 Características gerais do Samba de Roda Instrumentos O Samba de Roda é essencialmente uma roda de dança acompanhada por canto e percussão. Ainda que guitarras - instrumentos de corda dedilhada - ocupem uma função importante dentro do evento musical, elas são dispensáveis. Pois no samba, acontecimento espontâneo, empregam-se os instrumentos musicais - ou mesmo objetos - disponíveis no momento da roda. Pode-se esboçar a seguinte hierarquia dos instrumentos utilizados com maior frequência no Samba de Roda :

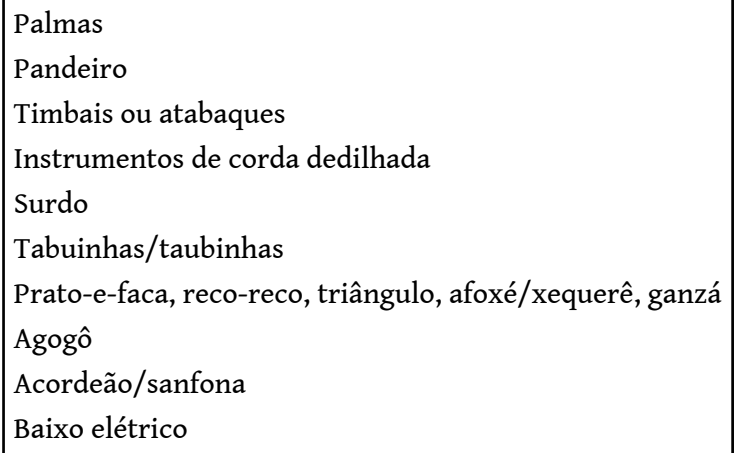

Ao longo dos últimos quarenta anos, constatam-se modificações nessa hierarquia, bem como a introdução de novos instrumentos como o baixo elétrico. Se antigamente o agogô servia de orientação temporal para os instrumentistas ao executar linhasrítmicas (PINTO, 2011), hoje ele é pouco empregado. 0 prato-e-faca, que nos anos 70 cumpria um papel especial (WADDEY, 1981, p. 254) e que é constantemente referido como instrumento característico do samba (CARNEIRO, 1974 ; ANDRADE, 1989), é tocado atualmente no Samba de Roda apenas por mestres mais velhos. 


\section{Estilo vocal}

7 A maneira de se cantar é um aspecto musical significativo para a diferenciação de gêneros musicais e para o reconhecimento de suas influências. Contudo, são poucos os recursos para descrever e representar as qualidades vocais e seus timbres (cf. TRAVASSOS, 2010). Faz-se necessário buscar instrumentos para se referir aos estilos vocais, pois, no caso do Samba de Roda, o estilo vocal demonstra ainda mais indícios de sua relação com tradições africanas e de suas recentes modificações.No Recôncavo Baiano nota-se uma diferença tímbrica evidente entre a fala dos jovens e dos mais velhos, que se reflete no canto. Waddey (1981, p. 209) e Oliveira Pinto (1991, p. 128) observaram a predominância de uma voz muito aguda no Samba de Roda e, no caso dos homens, o uso de falsete. Percebe-se, também, um canto de articulação difusa com voz estridente e anasalada. Alvarenga (1946) reconhece uma qualidade vocal semelhante, "um nasal afro-brasileiro" como sendo uma das "características de timbração dadas pelo fusionamento com o negro" (p. 370). A análise de espectrogramas ${ }^{2}$ indica que esse tipo de voz se caracteriza pela concentração de energia no primeiro harmônico da voz ${ }^{3}$, mais forte do que a própria nota fundamental :

8 Espectrograma da voz do puxador Primero 4 cantando "Vou ver Juliana" ${ }^{5}$ : Isso não ocorre, no entanto, com os cantores mais jovens, cujas vozes se assemelham às de cantores profissionais. Eles cantam com articulação clara, voz bem definida de emissão de peito, aspectos ensinados em aula de técnica vocal e que atendem a ideais de voz ocidentais. Um vocalista profissional, conhecendo técnica vocal ou não, pretende desenvolver um canto mais afinado, o que pode significar não apenas a entonação precisa das notas, como também a concentração dos harmônicos emitidos sobre determinadas frequências sonoras (FELD et al., 2004, p. 335). Outro fator que interfere na continuidade do estilo vocal tradicional do Samba de Roda vem a ser a amplificação dos instrumentos e das vozes. Ao usarem microfones, os cantores não precisam se esforçar para que sua voz se sobreponha ao acompanhamento instrumental, podendo cantar relativamente mais baixo e suave.

\section{Melodia e Harmonia}

O Samba de Roda compartilha de algumas características melódicas tipicamente africanas identificadas por Merriam ${ }^{6}$ (1956, p. 60-61) no candomblé-kétu :

- Tendência a frases melódicas descendentes ;- Extensão curta (cerca de uma oitava);

- Sequências de segundas maiores, terças e quartas ;- Ausência de modulação ;

- Ornamentação típica africana : portamento - ou glissando -, ataque ascendente (rising attack) e finalização descendente (falling release) ${ }^{7}$;

- Canto responsorial (call-and-response) ${ }^{8}$; Há ainda um aspecto comum entre o canto do candomblé e o do Samba de Roda não mencionado por Merriam : ambos os coros cantam em um movimento de vozes paralelo específico, o paralelismo vocal intervalar (Stimmbewegungsparallelismus), termo introduzido por Kubik (1983).

10 Apesar de todas as semelhanças, as cantigas do candomblé são modais, majoritariamente pentatônicas e sem semitons. Já o Samba de Roda parece fundamentar-se em escalas heptatônicas, ainda que muitas melodias se limitem ao uso de três até seis notas. Essas escalas são geralmente em tonalidades maiores ou em uma 
configuração melódica semelhante à do modo mixolídio. Os aspectos melódicos sugerem a existência de funções harmônicas inerentes - dominante e tônica. Inerentes, porque, mesmo na ausência de instrumentos harmônicos, as sequências intervalares das melodias correspondem à troca entre acordes de dominante e tônica. Contudo, na ausência de resoluções melódicas e de sequências de acordes claras nos instrumentos de corda, a presença dessas funções no Samba de Roda tradicional permanece questionável.

11 Embora a música tradicional africana muitas vezes apresente acordes, através de polifonia, heterofonia e homofonia vocal e instrumental, essas notas paralelas não cumprem funções harmônicas horizontais, mas formam, ao contrário, "clusters tímbrico-harmônicos" (timbric-harmonic clusters, KUBIK, 1999, p. 108). Para os músicos de influência africana, os clusters não fazem parte de uma hierarquia harmônica, na qual, por exemplo, um acorde de sol maior - a dominante - é mais importante que um acorde de fá maior - a subdominante -, ou mais tenso do que dó maior - a tônica. 0 acompanhamento harmônico do Samba de Roda parece ainda concordar com essa concepção africana, executando muitas vezes o que seria antes uma "sugestão de acordes" (suggestion of chords, EVANS, 1982, p. 26) que muitas vezes não coincide com a estrutura harmônica do canto.Apesar das estruturas melódicas e harmônicas do Samba de Roda corresponderem limitadamente à música tonal ocidental - presença de tonalidades maiores e formação de acordes indicando funções harmônicas - e demonstrarem uma tendência a ajustar-se a ela, sua influência africana ainda se faz evidente.

\section{Ritmo}

Ritmo é, segundo Platão, a ordem no movimento. Ritmo extrapola a sequência temporal de eventos sonoros - produzidos pelo movimento humano -, dizendo respeito a todos os movimentos, incluídos aí os coreográficos, linguísticos, etc. Ritmo não surge dentro de um evento musical, pelo contrário, a música que acompanha uma festividade é que representa apenas um dos aspectos da expressão rítmica da sociedade, especialmente de sociedades com forte influência africana. Kofi Agawu, ao referir-se a tradições ocidental-africanas, esclarece :

Eu acredito que a vitalidade dessa música é mais bem compreendida e apreciada no contexto de um esquema maior de expressão rítmica que envolve simplesmente todos os aspectos da vida tradicional ocidental africana. Expressão musical (ou essencialmente expressão rítmica) não se divorcia de outras formas de comunicação - linguagem, gestos, comprimentos e dança -, mas deriva diretamente desses. Grosseiramente falando, mas direto ao ponto : os africanos não se "tornam rítmicos" repentinamente na arena de seu vilarejo, onde eles diariamente realizam suas músicas e danças. Uma concepção unitária informa a variedade de maneiras pelas quais eles se expressam ritmicamente, seja na forma de brincadeiras ou canções infantis, música de rituais religiosos, músicas de trabalho, canções de protesto, fórmulas de comprimento, dança, ou a fala. ${ }^{10}$ (AGAWU, 1987, pp. 402-403, tradução livre).

13 Não há de ser por acaso, portanto, que justamente na organização rítmica das tradições musicais afro-brasileiras é que se encontram os mais fortes e evidentes traços africanos (cf. KAZADI, 1976; KUBIK, 1979; PINTO, 1991; 2001; GRAEFF, 2013). As mesmas concepções rítmicas de culturas africanas regem as danças e o fazer musical do samba, do candomblé, da capoeira, etc: hierarquia tímbrica (PANTALEONI, 1972), pulsos 
elementares (KUBIK, 1988), repetição cíclica de padrões rítmicos (KUBIK, 1988; RYCROFT, 1954), beats (MERRIAM, 1953; KOETTING, 1970) e linhas-rítmicas (PINTO \& TUCCI, 1992 ; time-line, NKETIA, 1991).

Sendo esse tema complexo e vasto, ele não será abordado aqui em mais detalhes e exemplos. É de relevância para a compreensão do Samba de Roda como performance, no entanto, ressaltar que o ritmo da percussão afirma o caráter do evento em questão, assim como dos passos da dança. Cantigas religiosas são acompanhadas geralmente em ritmo de marcha, podendo ser seguidas de sambas; procissões ou cortejos são acompanhados por ritmos de marcha ou ijexá, que favorecem o caminhar pelas ruas, acentuando e dividindo os passos em "um e dois". Isso significa que, diferentemente do carnaval do Rio de Janeiro, no Recôncavo Baiano a tradição não é de se executar samba durante os cortejos pelas ruas, fato que corrobora a teoria de que o samba tenha sido adaptado no Rio de Janeiro para acompanhar o carnaval (cf. SANDRONI, 2001, p. 137). Ainda que o ritmo de samba se faça presente na maioria das celebrações religiosas ou seculares, ele costuma ser executado em seu encerramento, quando do abandono da esfera solene e sagrada (cf. MARQUES, 2008, p. 129). O Samba de Roda parece, assim, marcar o retorno ao cotidiano.

\section{Dança}

15 As diferentes formas de samba do Recôncavo Baiano compartilham das mesmas características coreográficas : a roda, o miudinho e a umbigada. A roda é formada pelos músicos e pelos participantes, que cantam em coro, batem palmas e ficam à espera de sua vez de entrar nela, individualmente. Com a recente comercialização do Samba de Roda, que o torna um evento de palco, sua própria característica fundamental, a roda, se dissolve. Os integrantes do grupo, músicos e sambadeiras, ficam no palco em frente ao público, que dança simultaneamente e sem formar um círculo, marcando uma clara separação entre músicos e espectadores, entre "profissionais" e "amadores". A umbigada originou-se de danças angolanas (CARNEIRO, 1974, pp. 35-39) e consiste em encostar ou insinuar o encosto entre os ventres daquele que sai e daquele que entra na roda. Podendo ser substituída por um bater de palmas apontando em direção ao próximo dançarino, a umbigada vem perdendo importância na performance, de maneira que os dançarinos se revezam sem qualquer sinalização evidente. Outros passos tradicionais como o corta-a-jaca, separa-o-visgo e apanha-o-bago, amplamente citados na literatura do samba, são raramente executados em nossos dias.

o miudinho é uma forma de dança histórica mencionada por diversos pesquisadores ao longo de todo o século XX, seja em relação ao samba baiano ou ao tradicional carioca. Seu nome refere-se aos passos quase imperceptíveis dos pés, que são arrastados em curtos movimentos sem sair do chão. Ainda que os três estilos do Samba de Roda comparilhem das mesmas formas de dança, eles diferenciam-se em suas regras de performance. Tal divergência observou Waddey em relação ao Samba Corrido e o Samba Chula (aqui denominado samba-de-parada) :

Samba de parada refere-se ao fato de os cantores pararem de cantar enquanto um dançarino dança e o dançarino parar de dançar enquanto o cantor canta. No Samba Corrido, por outro lado, o canto e a dança não apenas são contínuos e simultâneos, mas diversos dançarinos podem entrar na roda de uma vez só, o que é rigorosamente proibido no samba de parada. ${ }^{11}$ (WADDEY, 1981, p. 258, tradução livre). 
17 Esse seria também motivo da preferência dos mais velhos pelo Samba Chula, enquanto o Samba Corrido seria "uma coisa de suar a camisa"12. Francisca Marques, em suas pesquisas sobre o samba de Cachoeira, identificou coreografias específicas do Samba de Barravento, que variam de acordo com o dançarino. Essas coreografias, que incluiriam pausas na dança durante as partes cantadas, aproximariam esse estilo de Cachoeira ao samba de parada (MARQUES, 2003, p. 80-81, 101).

\section{Conteúdo dos Textos}

18 As letras do Samba de Roda são cantadas em português. Conteúdo e forma variam de acordo com o estilo regional. É comum a todos os estilos, no entanto, o fato dos textos serem em grande parte improvisados e oriundos de ditos e canções populares. Antigas expressões, cantigas e contos se mesclam com acontecimentos cotidianos e, sobretudo, com acontecimentos imediatos da performance. Por essa razão, uma única melodia pode ter textos variados, bem como um mesmo tema pode ser entoado de diversas formas.Algumas canções tratam de assuntos locais, relatando fatos contemporâneos ou históricos. A nomeação do Samba de Roda como patrimônio cultural imaterial brasileiro (2004) foi comemorada pela mestra Dalva Damiana de Freitas através da seguinte composição, que ao mesmo tempo celebra o passado (trazer de volta o trem e o barco a vapor) :

Graças a Deus que as coisa melhorou

As festas de Cachoeira, todas elas levantou

Foi chegado o patrimônio, consertado o bangalô

Me traga de volta o trem, me traga de volta o vapor

19 A história do Brasil também é representada nos textos do samba de Roda: Imperador, Imperador, 13 de maio demorou, mas já chegou ${ }^{13}$

Um assunto recorrente que chama a atenção é a traição ou poligamia. Não pelo homem, como é de se esperar, mas pela mulher :

No Paraguaçu não tem piranha $(2 \mathrm{x})$

Jacaré nada de bruços

A mulher com dois maridos

E nem é o fim do mundo ${ }^{14}$

21 É natural que os cantores, em sua maioria homens, relatem suas próprias dores, porém é curioso e que a traição seja uma queixa comum. Não se trata de mera coincidência : os textos retratam a realidade social presente ou passada. Prova disso é o seguinte comentário de Oliveira Pinto: “inesperado para um país tido como patriarcal é a grande porção de troca de parceiro pela mulher, tanto na Ilha do Dendê como em outras partes do Recôncavo"15 (1991, p. 26, tradução livre). Talvez seja equivocado, mas de todo modo possível, remontar a infidelidade das mulheres aos tempos da escravidão, já que os senhores mantinham intencionalmente em suas propriedades um número de mulheres inferior ao dos homens (cf. SCHWARTZ, 1988). Temas de tradições folclóricas encontradas por todo o Brasil costumam ressurgir no Samba de Roda, podendo ser cantados em uma roda independente de uma data festiva. Exemplos disso são as canções sobre santos católicos, sobre o boi do bumba-meu-boi e os três reis magos dos ternos de reis. Dois versos de uma chula cantada pelo grupo Samba Chula de São Braz trazem um tema característico do folclore do Rio Grande do Sul, o balaio ${ }^{16}$. A canção 
gaúcha é entoada até os dias de hoje em festividades tradicionais, em uma versão um pouco diferente da baiana :

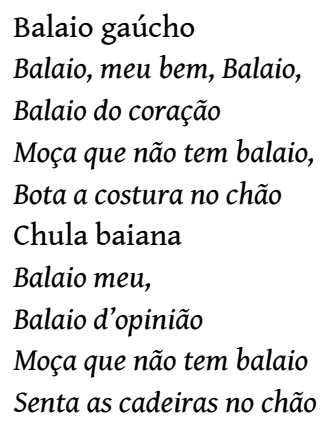

22 É interessante notar que a palavra "balaio" é interpretada de maneira distinta em cada um dos textos. No gaúcho ela se refere ao balaio de costura, cujo formato arredondado é aludido quando as dançarinas rodam suas saias. Assim, a moça que não tem balaio não pode guardar sua costura, tendo que deixá-la no chão. No texto baiano, balaio refere-se ao balanço dos quadris da dançarina, ou ao seu talento de balançá-los, pois se ela não tem balaio, fica sentada com as "cadeiras", isto é, com os quadris no chão. Apesar de o balaio ser tradição significativa do folclore do Sul e praticamente ausente na Bahia, o próprio Guia do Folclore Gaúcho (MEYER, 1975) desmente a suposição de que o balaio seja de origem açoriana e gaúcha: "O balaio é brasileiro da gema e procede do Nordeste ; chula baiana ou lundu pernambucano, entrou nos fandangos do Sul sem perder a marca original" (p. 13). Provavelmente uma mesma tradição poética açoriana foi difundida em ambas as regiões, assimilando ritmos e significados diferentes.

\section{Estilos Regionais}

Existem várias denominações para os sambas praticados no Recôncavo Baiano, ora identificando um "mesmo fenômeno, mas chamando-o de acordo com seus aspectos específicos"17 (WADDEY, 1981, p. 252, tradução livre), ora designando fenômenos divergentes. Aqui serão analisados os três estilos de Samba de Roda mais recorrentes e reconhecidos em toda a região, que apresentam, além das diferenças coreográficas citadas antes, particularidades musicais ${ }^{18}$ : Samba Corrido, Samba Chula e Samba de Barravento.

\section{Samba Corrido}

Corrido significa na Capoeira cantigas com textos curtos entoados por uma só pessoa e repetidos por um coro. A palavra "corrido" refere-se não necessariamente à velocidade da música, mas ao caráter da performance, onde cantores e dançarinos se alternam continuamente. Mário de Andrade (1989) identifica o termo "corrido" como "uma das denominações do batuque" (p.157), dando um exemplo das comuns contradições terminológicas relacionadas a tradições afro-brasileiras. O Samba Corrido também pode ser chamado de samba-solto.

O puxador do samba parece não improvisar muito na estrutura dos versos no Samba Corrido ; algumas palavras podem ser modificadas dentro de uma mesma melodia que é repetida até a introdução de uma nova música. $O$ texto varia de acordo com princípios semelhantes aos de culturas africanas : 
Quando unidades inteiras são repetidas, algumas palavras dessa unidade podem ser individualmente substituídas por outras, por exemplo um nome próprio ou outros termos, dependendo da vontade e da disposição do puxador dos versos, ou das exigências de cada situação. Se essa técnica de substituição é usada corretamente, canções antigas podem receber uma nova versão com a função de elogiar, alertar, agradecer, debochar ou adular alguém, quando for oportuno. ${ }^{19}$ (NKETIA, 1991, p. 219, tradução livre).

Muitos grupos partilham dos mesmos corridos, isto é, das mesmas melodias com textos similares. Por exemplo, é comum a execução de um mesmo corrido alterando apenas o local dos músicos em questão :

Samba Corrido com melodia única e texto alterado ${ }^{20}$

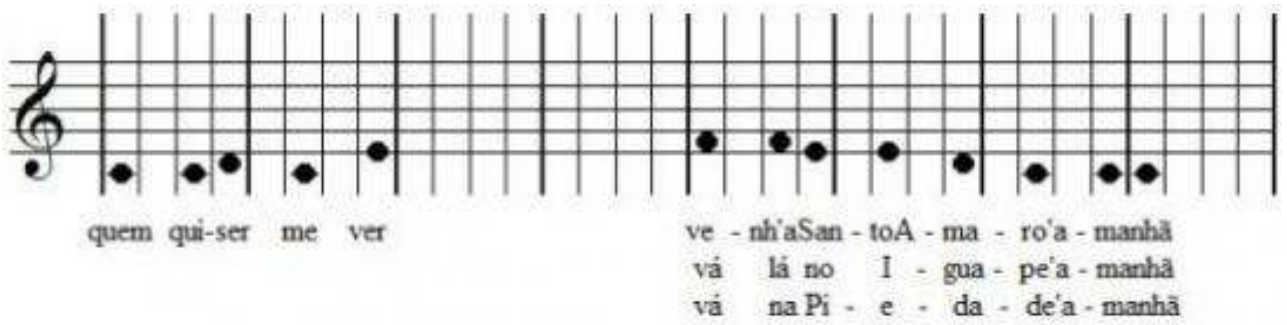

As duas primeiras versões são de grupos de Santo Amaro e de Santiago do Iguape. A terceira versão trata-se de uma citação - sem melodia - de Edison Carneiro (1974), referindo-se à Praça da Piedade em Salvador, que seria um "refúgio do samba, por ocasião do Carnaval" (p. 69) até meados de 1930. Esse é apenas um exemplo de inúmeros Sambas de Roda transmitidos há longo tempo, em diferentes regiões da Bahia, e ainda presentes no Recôncavo.

\section{Samba Chula}

O Samba Chula não foi pouco documentado, no entanto sob diferentes nomes. Se na época da pesquisa de Ralph Waddey e de Tiago de Oliveira Pinto o termo samba-de-viola era mais comum, atualmente se identifica o mesmo estilo principalmente como Samba Chula. Waddey (1981, p. 252) ainda menciona outras denominações relativas à mesma tradição : samba amarrado, samba de parada, samba chulado, samba de partido alto e samba sant'amarense. Muitos são os aspectos que reúnem todos esses termos em uma única tradição musical. o samba-amarrado tem seu contraponto no samba-solto, sinônimo de Samba Corrido. Essas denominações não se relacionam apenas ao fato de um ser mais "duro", como julgam os mestres, ou seja, mais difícil que o outro, mas principalmente à forma do canto. Amarrar tem um significado específico na música de diferentes formas de desafio - jongo, côco e embolada-, que Travassos (2010a) define da seguinte maneira: "Amarrar é ligar versos em sequências, de acordo com modelos métricomusicais conhecidos, sem ser interrompido pelo refrão coral ou pela resposta do embolador-parceiro" (p. 27).

Chula é uma forma de dança e canção portuguesa ${ }^{21}$ que se espalhou de variadas maneiras pelo Brasil (ANDRADE, 1989, p. 139). No Recôncavo Baiano, o termo se refere à forma específica do texto e de como ele é cantado. Döring (2010) resume a estrutura das chulas baianas :

[Chula] no Samba Chula é o canto de uma estrofe composta por dois até quatro versos, entoado por uma parelha (dupla vocal) quase sempre de homens. Ao 
contrário do Samba Corrido, o verso não é respondido e repetido pelo coro, à maneira do canto responsorial. A chula pode passar uma mensagem clara ou ser simbólica, como metáfora ou poesia livre, cujo significado em alguns casos se perdeu no tempo ou só se faz compreender entre os mais velhos. Geralmente, a chula é seguida de um relativo, uma estrofe um pouco mais curta cantada por outra parelha, concluindo ou comentando a chula de uma maneira muitas vezes engraçada. ${ }^{22}$ (DÖRING, 2010, s. n., tradução livre)

30 A segunda voz da parelha canta geralmente uma terça abaixo de quem puxa os versos, tendo que prestar atenção constante na improvisação do puxador, a ponto de poder reproduzir quase que simultaneamente os versos. Duplicar a melodia uma terça abaixo é tarefa mais simples, pois previsível, já que as chulas obedecem a fórmulas rítmicomelódicas. Grande parte delas começa em uma frequência mais aguda, geralmente a oitava, e descem até a terça fundamental. A semelhança formal e melódica entre chulas de diferentes regiões do Recôncavo se faz evidente através de espectrogramas :

\section{Espectrogramas de chulas com melodias semelhantes $^{23}$}

Os gráficos visualizam as vozes de dois cantadores de chula cantando sem acompanhamento textos diferentes. Os três padrões rítmico-melódicos se compõem de dois versos separados por uma pausa entoados em movimento descendente, iniciando na oitava e finalizando na terça, entre outros aspectos. O canto do Samba Chula tem mais uma característica marcante: a presença da sétima menor, que indicaria o emprego do modo mixolídio ${ }^{24}$ caso sua ocorrência fosse regular. Entretanto, o canto parece "oscilar" (IPHAN, 2006, p. 51) entre sétimas menores e maiores, ou mesmo alterná-las sistematicamente. Talvez haja uma regra para o emprego de cada uma, já que elas são cantadas exatamente nos mesmos lugares de uma fórmula rítmicomelódica executada por diferentes intérpretes. Todavia, analisando-se diversas fórmulas fica difícil determinar a razão em se cantar cada nota em uma parte específica da melodia.

Outra questão complexa trata-se da afinação da terça final (dó3 e mi3), que não forma um intervalo nem maior, nem menor. Sob uma perspectiva estética ocidental, se consideraria que as parelhas do Samba Chula simplesmente desafinam. Porém, uma análise mais adequada desta particularidade pode revelar suas verdadeiras origens. Explicação para essa escala especial do Samba Chula, acompanhada pelo canto em intervalos paralelos, seria sua possível origem angolana, conforme Kubik (1979) :

A presença de modalidade e terças paralelas na versão "angolana" do Samba das ruas poderia ser facilmente interpretada como sendo portuguesa. Contudo, o fato é que, nesse contexto dos sistemas tonais e cantos polifônicos, os traços angolanos e portugueses reforçaram uns ao outros no Brasil. A escala quase-equiheptatônica do interior da Angola ligada estruturalmente com o canto em sequências de terça (neutras) e quartas ou de terças e quintas, junto com o sistema tonal diatônico da música folclórica da Europa ocidental ligado ao canto em terças menores/maiores paralelas, formaram uma fusão perfeita no Brasil. Música iorubá, por outro lado, continuou na Bahia com seu sistema pentatônico e ausência de canto polifônico. ${ }^{25}$ (KUBIK, 1979, p. 22, tradução livre).

O último aspecto do Samba Chula a ser mencionado é o papel central da viola. Ela é de tal maneira importante para o estilo que lhe confere uma de suas denominações: samba-de-viola. Antigamente essa era a mais comum, como justifica Waddey (1981) : "É a 
viola, sua presença na performance do gênero e seu significado para a ocasião que mais caracterizam esse samba para os seus participantes" (p.196). Não era tanto o instrumento que caracterizava o estilo, mas principalmente a maneira como ele era tocado, através de fórmulas acústico-mocionais (PINTO, 2001) que remontam a técnicas de execução instrumental africanas, os toques ou tons-de-machete (cf. PINTO, 1991; PINTO \& GRAEFF, 2012).

Tendo em conta todas essas características do Samba Chula, torna-se fácil identificá-lo em relatos históricos. Confusões terminológicas são contornadas ao reconhecermos nas descrições dos fenômenos culturais seus traços particulares. Tomemos a colocação de Sílvio Romero datada do século XIX como exemplo (trechos sublinhados pela autora) :

Chama-se chiba na província do Rio de Janeiro, samba nas do norte, caterêtê na de Minas, fandango nas do sul uma funç̧ão popular da predileç̧ão dos pardos e mestiços em geral, que consiste em se reunirem damas e cavalheiros em uma sala ou n'um alpendre para dansar e cantar. Variadas são as tocatas e as dansas.

Ordinariamente porém consiste o baile rústico em sentarem-se em bancos à roda da sala os convidados, e, ao som de violas e pandeiros, pular um par ao meio do recinto a dansar com animação e requebros singulares o bahiano ou outras variações populares. O bahiano é dansa e musica ao mesmo tempo. Os figurantes em uma toada certa têm a faculdade do improviso em que fazem maravilhas, e os tocadores de viola vão fazendo o mesmo, variando os tons. Dados muitos gyros na sala, aquelle par vai dar uma imbigada noutro que se acha sentado e este surge a dansar. $O$ movimento se anima, e, passados alguns momentos, rompem as cantigas populares e começam os improvisos poéticos. (ROMERO, 1888, p. 33)

Romero parece descrever um típico Samba de Roda. Primeiramente entra em cena o Samba Chula, de canto improvisado (toada), acompanhado por pandeiros e violeiros que variam os tons-de-viola. A troca de dançarinos, aqui em pares, é sinalizada pela umbigada. $\mathrm{O}$ andamento das músicas vai se acelerando, até irromper em "cantigas populares" - em corridos, e não mais chulas improvisadas - e começam os improvisos poéticos - do puxador dos versos. A mesma ordem de acontecimentos do Samba Chula ao Samba Corrido - ainda é comum na Bahia.

Samba Chula demonstra uma grande afinidade com culturas musicais do sertão nordestino. Tendo-se em conta que esse estilo de samba cumpre um papel especial dentro do candomblé de caboclo e que a viola é o instrumento musical da figura do boiadeiro, somos levados para outra área geográfica da Bahia. Se nas lavouras do Recôncavo Baiano trabalhavam predominantemente escravos africanos, as bandeiras e a criação de gado do sertão se prestavam da mão-de-obra indígena (FILHO, 2008, p. 183). A figura do boiadeiro com sua viola remete historicamente ao índio ou ao caboclo, e não ao negro. A letra da canção "Mandamentos de caboclo", gravada em 1938 pela dupla Alvarenga e Ranchinho confirma a relação entre esse tipo de música e o caboclo. A música traz semelhanças musicais com o Samba Chula : canto com sétima menor em terças paralelas, acompanhado por viola, alternando entre partes cantadas e partes de viola solo. 0 ritmo marcado pela viola é, no entanto, de marcha e não de samba. Os mandamentos entoados pela parelha expressam que o caboclo deve "pontear uma viola desde o baixo até o alto" e "aguentar em um desafio um caboclo bom de trova". Talvez as origens do Samba Chula se encontrem nas fronteiras do Recôncavo com o sertão baiano. 


\section{Samba de Barravento} o Samba Chula -, na atualidade as duas formas parecem ter se fundido musicalmente quase que por completo. Instrumentação, harmonia e forma musical são praticamente idênticas nas gravações e apresentações dos sambas da região de Cachoeira. Talvez as 
melodias dos sambas de Cachoeira possam oferecer indícios de sua diferenciação, contribuindo ainda para o entendimento de sua fusão. Waddey descreveu e transcreveu "uma característica recorrente no Samba-de-viola que é (...) identificada e denominada pelos próprios cantores (um caso raro, em contraste com o extenso vocabulário teórico aplicado à viola e a seu uso) de baixão - uma sensível na oitava abaixo sustentada na sílaba final do penúltimo verso" (1981, p. 257, tradução livre ${ }^{27}$. O baixão se encontra em vários Sambas Chula, assim como em sambas de Cachoeira. Seria uma coincidência que justamente esses sambas de Cachoeira tenham um andamento sutilmente mais lento que outros?

Baixão em "Rio Paraguaçu” (excerto), Grupo Filhos de Nagô, de São Félix

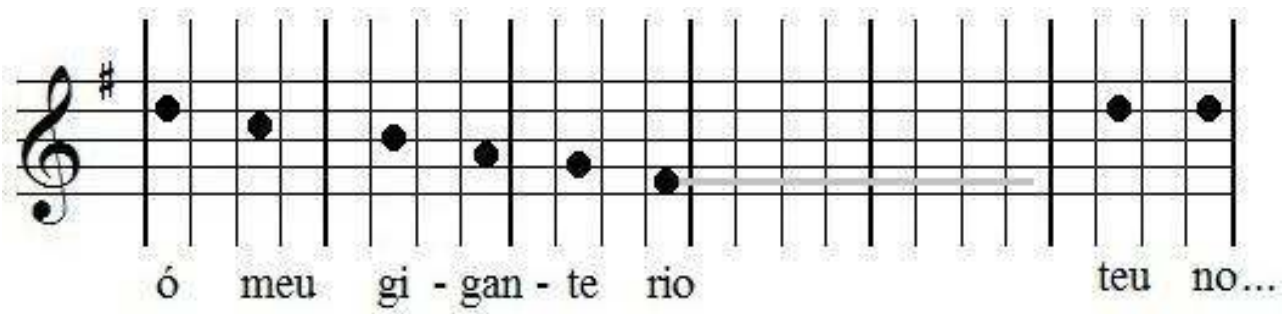

- = Sustentação da nota : baixão

De fato parece ter existido uma forma de samba em Cachoeira muito semelhante ao Samba Chula. E se hoje ainda existe o Samba Corrido, por que não acreditar que o Samba de Barravento era uma das denominações do Samba Chula na região ? característica do Samba Chula - não apenas no canto, mas também na ponte instrumental $^{28}$. Isso nos remete à similitude entre as fórmulas melódicas do Samba Chula e a ponte instrumental do Samba de Barravento. Nota-se que ambas são executadas em terças paralelas, em movimento descendente, iniciando na oitava e terminando na terça fundamental e, finalmente, costumavam alternar entre sétimas maiores e menores. Os mesmos elementos caracterizam a ponte instrumental da viola na canção mencionada anteriormente, "Mandamentos do caboclo". A viola repete no seu solo uma sequência de terças paralelas em movimento descendente.De onde teria surgido, afinal, o Samba de Barravento e a ponte instrumental acórdica que lhe confere seu nome ?Na música "Dindinha" do Grupo Barravento de Salvador, um narrador explica o que é o Samba de Barravento, enquanto os outros integrantes executam um exemplo musical. Este é executado muito lentamente por duas vozes em terças paralelas e uma viola rasgando acordes como em tremolo - repetição rápida sem um determinado ritmo. Para o narrador, esse samba era cantado durante o trabalho de construção de casas, "depois da casa pronta, vinha a celebração, e esse samba de barravento virava um samba de roda".

Música e função semelhantes podem ser observadas em um vídeo do arquivo de Oliveira Pinto documentando um lindramô, cortejo com o propósito de arrecadar fundos para as cerimônias de candomblé (PINTO, 1991), atualmente quase extinto na região. Inicialmente, os participantes dançam pelas ruas com acompanhamento percussivo em ritmo ijexá sendo guiados pela líder, a mãe-de-santo do terreiro de candomblé de caboclo em questão, que carrega um estandarte. Eles passam de casa em casa até um anfitrião convida-los para entrar, o que significa sua disposição a contribuir com a arrecadação. Em frente à casa que os vai receber, eles param e cantam uma chula com 
baixão, acompanhada apenas por uma viola machete, que rasga acordes como em tremolo. Ao final da chula, que termina sustentando a terça fundamental, os instrumentos de percussão começam de imediato a puxar o ritmo de samba, e todos os participantes se dirigem para dentro da casa, onde a roda de samba (corrido) se instala. No fim do samba são oferecidas bebidas e as doações (PINTO, 1991, p. 158).

Muito similar a esse desenvolvimento é a descrição de Guilherme de Melo dos ranchos populares datada de 1908, confirmando a função da chula de sinalizar um momento de transição do evento :

Lá se foram (...) à Lapinha adorar o menino Deus ao som da flauta, do pandeiro, do cavaquinho, da viola e do ganzá. De volta, vinham sambando [ou "marchando" e dançando ao ritmo de ijexá ?] de casa em casa, para o que, mediante aviso feito de ante-mão, tinham assentimento de seus donos. Aí, após uma chula alusiva ao rancho, eles fechavam e arrojavam o samba, segundo seu modo de dizer, debaixo de comes e bebes. (MELO, 1947, p. 36).

47 A parte musical de mudança entre ijexá e samba, entre via pública e ambiente privado, entre cortejo e comemoração é feita pela chula acompanhada pela viola. Essa parte musical seria o barravento, o momento de transição que "virava um samba de roda". Os acordes em tremolo, que davam sustentação à melodia da chula, teriam ganhado uma versão fixa, a ponte instrumental barravento. A forma de samba que a emprega viria a se denominar Samba de Barravento. Tais hipóteses são corroboradas pela descrição de Mário de Andrade do batuque, que provavelente se tratava de um Samba de Roda:

No seu tipo mais generalizado consta de uma roda na qual fazem parte, além dos dançarinos, os músicos e os espectadores. No centro da roda fica um dançarino solista, ou um ou mais pares a quem pertence realmente a coreografia. A dança consiste em meneios violentos das ancas, sapateados, palmas, estalar de dedos; apresenta como elemento específico a umbigada que o dançarino ou dançarinos solistas dão nos figurantes da roda que escolhem para substituí-los. A introdução ou prelúdio da dança chama-se baixão e é executada pelo violeiro. (ANDRADE, 1989, p. 53).

As observações de Mário de Andrade evidenciam as contradições terminológicas na história da música brasileira, ao denominar-se batuque o que também se conhece como Samba de Roda. É de se imaginar que confusão semelhante tenha ocorrido quando Andrade se refere, aparentemente, ao barravento da viola, à sua introdução acórdica. Intitulando-a, corretamente ou não, "baixão", o autor confirma a função especial desse termo no que ele chama de "prelúdio da dança" e que o presente trabalho entende agora por barravento.

\section{Conclusões}

Através dos inúmeros dados extraídos da análise do Samba de Roda, foi possível resgatar indícios de suas origens e desenvolvimento ao longo da história. Estabelece-se um diálogo entre traços musicais e coreográficos - transformados agora em marcas de historicidade - e seus contextos atuais e históricos. A partir daí, precisam-se o lugar e o grau das influências africanas, portuguesas, sertanejas ou caboclas na prática musical, contribuindo para a compreensão dos referentes identitários ali implícitos, que, especialmente no caso do Samba de Roda, são predominantemente imateriais.A roda de samba não celebra uma data ou um acontecimento específico, porém não deixa de ser um rito. Nela se expressam valores, costumes, símbolos da comunidade advindos de 
escravos africanos, indígenas e de senhores portugueses. Ditos, ritmos, melodias e movimentos são elevados a "coisa social" (DAMATTA, 1997) ao serem incorporados no evento, afirmando a identidade e a singularidade do grupo. $O$ passado dos afrobrasileiros é relembrado e eternizado na roda. Talvez o Samba de Roda trate-se da manifestação mais evidente da identidade afro-brasileira do Recôncavo Baiano, finalizando grande parte das festividades da região, como que marcando, no caso de cerimônias religiosas (cf. MARQUES, 2008, p. 129), a volta ao profano, assim como a volta ao cotidiano. Pois de acordo com o sambador Primero, de Santo Amaro da Purificação, um domingo inteiro de samba não fatiga, pelo contrário : "dá força" para recomeçar a rotina na segunda-feira seguinte. Esperanças são renovadas ao se sentir no ritual a própria "continuidade como grupo" (DAMATTA, 1997, p. 30). No Recôncavo da Bahia, sambar é comemorar através do corpo a própria memória e identidade.

\section{BIBLIOGRAFIA}

ALVARENGA, Oneyda. (1946). “A influência negra na música brasileira”, In : Boletin Latino Americano de Música V/6 (abril 1946). 346-407.

ANDRADE, Mário de. (1989). Dicionário Musical Brasileiro. Org. Oneyda

ALVARENGA e Flávia CAMARGO Toni, São Paulo : Itatiaia.

CARNEIRO, Edison. (1974). Folguedos Tradicionais. Rio de Janeiro : Conquista (1961).

DAMATTA, Roberto. (1997). Carnavais, malandros e heróis : para uma sociologia do dilema brasileiro. $6^{\mathrm{a}}$ ed. Rio de Janeiro : Rocco.

DÖRING, Katharina. (2010). "Samba Chula do Recôncavo Baiano - Tanz, Musik, Spiel und Lebensfreude !”, In : Popscriptum 11 - The Groove issue. s.n.

EVANS, David. (1982). Big Road Blues. Tradition and Creativity in the Folk Blues. Berkeley: University of California Press.

FELD, Steven; FOX, Aaron A.; PORCELLO, Thomas; SAMUELS, David. (2004). "Vocal Anthropology. From the Music of Language to the Language of Song", In: A Companion to Linguistic Anthropology, org. Alessandro Duranti. Massachussets : Blackwell. 321-346.

FILHO, Luiz Vianna. (2008). o Negro no Brasil. $4^{a}$ edição. Salvador : EDUFBA.

GRAEFF, Nina. (2012). „Reflexos da nomeação do samba de roda como Obra-Prima da Humanidade pela UNESCO sobre a cultura do Recôncavo Baiano", in : Musics and knowledge in Transit / Músicas e saberes em trânsito / Músicas y saberes en tránsito, hrsg. von Susana Moreno

FERNÁNDEZ, Pedro Roxo e Iván IGLESIAS. Lisboa : Colibri. DVD-Rom.

FERNÁNDEZ, Pedro Roxo e Iván IGLESIAS (2013). “Rhythmische Strukturen des Samba de Roda aus dem Recôncavo Baiano“, in : XX Berichte aus dem ICTM-Nationalkomitee Deutschland 2011. No prelo.

IPHAN. (2006). Samba de roda do Recôncavo Baiano - Dossiê 4. 
KAZADI wa Mukuna. (2006). Contribuição Bantu na Música Popular Brasileira. Perspectivas Etnomusicológicas. São Paulo : Terceira Margem.

KUBIK, Gerhard. (1979). Angolan traits in black music, games and dances of Brazil. A study of African cultural extensions, Lisboa : Junta de Investigações Científicas do Ultramar.

KUBIK, Gerhard. (1983). "Mehrstimmigkeit in Zentral- und Ostafrika”, In: Musik in Afrika. Mit 20 Beiträgen zur Kenntnis traditioneller afrikanischer Musikkulturen, org. Artur Simon, Berlin: Museum für Völkerkunde. 27-40.

KUBIK, Gerhard. (1999). Africa and the Blues. Jackson: University Press of Mississippi. Marques, Francisca. (2003). o Samba de roda em Cachoeira, Bahia. Uma abordagem etnomusicológica. Dissertação de mestrado, Universidade Federal do Rio de Janeiro 2003.

KUBIK, Gerhard. (2008) Festa da Boa Morte e Glória. Ritual, Música e Performance. Tese de doutorado, Universidade de São Paulo.

MELO, Guilherme de. (1947). A música no Brasil. $2^{a}$ edição (1908). Rio de Janeiro : Imprensa Nacional.

MERRIAM, Alan P. (1956). "The Songs of the Ketu Cult of Bahia, Brazil“, In: African Music Bd. 1/3, Johannesburg 1956. 53-67.

MERRIAM, Alan P. (1959). “African Music”, In: Contituity and Change in African Cultures, org. William R. Bascom e Melville J. Herskovits, Vhicago e Londres: The University of Chicago Press. 49-86.

MEYER, Augusto. (1975). Guia do Folclore Gaúcho, 2. Ed. Rio de Janeiro : Presença.

NKETIA, Joseph H. KWABENA. (1991). Die Musik Afrikas. 2ª edição. Trad. Claus Raab, Wilhelmshaven : Noetzel.

NUNES, Raquel Pereira Alberto. (2011) “Barravento. Um filme, duas histórias”, In : Razón y Palabra 76 (Maio-Julho 2011).

PANTALEONI, Hewitt. (1972). “Three Principles of Timing in Anlo Dance Drumming“, In: African Music 5/2, Transvaal. 50-64.

POMIAN, Krzystof. (1999). Sur l'histoire. Paris : Gallimard.

PINTO, Tiago de Oliveira ; Graeff, Nina. (2012). "Música entre materialidade e imaterialidade : os tons-de-machete do Recôncavo Baiano", in : Revista Mouseion 11 (jan-abr). 72-97.

PINTO, Tiago de Oliveira e Tucci, Dudu. (1992). Samba und Sambistas in Brasilien. Wilhelmshaven : Florian Noetzel.

PINTO, Tiago de Oliveira. (1991). Capoeira, Samba, Candomblé. Afro-brasilianische Musik im Recôncavo, Bahia. Berlim : Museum für Völkerkunde.

PINTO, Tiago de Oliveira. (2001). “As cores do som. Estruturas sonoras e concepções estéticas na música afro-brasileira“, In : África. Revista do Centro de Estudos Africanos 22-23, USP, São Paulo 1999-2001. 87-109.

ROMERO, Silvio. (1883). Cantos populares do Brasil. Volume 1. Lisboa : Nova Livraria Internacional. ROMERO, Silvio. (1888). Estudos sobre a poesia popular do Brazil. Rio de Janeiro: Laemmert.

RYCROFT, David R. (1954). „Tribal Style and Free Expression”, In: African Music vol. 1/1954. 16-27. SANDRONI, Carlos. (2001) Feitiço decente. Transformaç̧̃es do samba no Rio de Janeiro 1917-1933. Rio de Janeiro : Jorge Zahar/Ediora UFRJ. 
SCHWARTZ, Stuart B. (1988). Segredos internos. Engenhos e escravos na sociedade colonial. Trad. Laura Teixeira Motta, São Paulo : Companhia das Letras.

TRAVASSOS, Elizabeth. (2010a). "Palavras que consomem. Contribuição à análise dos cocos-deembolada", In : Revista IEB 50 (setembro-março 2010), S. 13-40.

TRAVASSOS, Elizabeth. (2010b). "Ritos orales, cantometrics y otros pasos en dirección a una antropología de la voz". A Contratiempo 14.

WADDEY, Ralph. (1981) "Viola de Samba and Samba de Viola in the Recôncavo of Bahia (Brazil)", In: Latin American Music Review, 1980/81, volume 1/2, p. 196-212. Volume 2/2, p. 252-279.

ZAMITH, Rosa Maria. (1995). “O Samba-de-Roda Baiano em Tempo e Espaço”, In : Revista Interfaces, no 2 (1995). 53-66.

\section{Referências Audiovisuais}

DÖRING, Katharina (org.). (2009). Cantador de Chula. DVD e 2 CDs. Esmola Cantada da Ladeira da Cadeia.

Esmola Cantada Santa Cruz da Ladeira da Cadeia. 25 faixas e versos cantados com muito samba de roda. CD.

GRUPO BARRAVENTO. (s.d.). Barravento. CD.

INSTITUTO MOREIRA SALLES. Acervo Digital. http://acervo.ims.uol.com.br/ [10.09.2012].

IPHAN. (2006). Samba de Roda. Patrimônio da Humanidade. CD. Nicinha e Raízes de Santo Amaro (s.d.). Nicinha e Raízes de Santo Amaro. CD.

PINTO, Tiago de Oliveira. Documentação audiovisual de campo (1984 e 1987).

PINTO, Tiago de Oliveira (org.). (1990). Capoeira, samba, candomblé: Afro-Brazilian Music in Bahia. CD.

QUIXABEIRA Da MATINHA. (2010). Cheguei pra sambar. CD.

SAMBA CHULA De SÃO BRAZ. (2010). Quando dou minha risada, há, há. MinC/FUNARTE. CD.

SAMBA TRADICIONAL Da ILHA. (2005). Aruê Pã (2005). CD.

SAMBA De RODA FILHOS De NAGÔ. (2004). Viola Velha. CD.

SAMBA De RODA De SUERDIECK. (s.d.). Samba de Dalva. CD.

TRAVASSOS, Elizabeth ; ZAMITH, Rosa Maria (org.). (1994). Samba de Roda no Recôncavo Baiano. CD. FUNARTE.

\section{NOTAS}

1. O pesquisador Tiago de Oliveira Pinto disponibilizou seu vasto arquivo de vídeos e gravações sonoras feitas entre 1982 e 1992. O material coletado por Rosa Zamith e Elizabeth Travassos (1994) também foi analisado.

2. Espectrogramas são representações visuais tridimensionais de sinais de áudio, mostrando a concentração de energia dos sons no tempo- horizontalmente - e no seu espectro de freqüências - verticalmente.

3. Os harmônicos ou sobretons são componentes de um sinal sonoro quase imperceptíveis para os ouvidos humanos. Sua configuração é responsável pela diferenciação entre timbres de instrumentos e vozes, sendo chamada de formante. 
4. Rogaciano Augusto de Carvalho, de Santo Amaro da Purificação.

5. A primeira linha, de baixo para a cima, é a nota fundamental, aquela que identificamos como a nota sendo cantada, enquanto que as outras linhas adjacentes representam os seus harmônicos.

6. Alvarenga (1946) também analisou rigorosamente as melodias do candomblé, reconhecendo algumas dessas características antes de Merriam.

7. No ataque ascendente há um pequeno portamento antes de se atingir a nota real da melodia, e, na finalização descendente, após chegar na nota final. Ver espectrograma anterior.

8. No conceito do call-and-response há um "puxador" - cantor - que "puxa", isto é, canta primeiro o texto e melodia a serem repetidos por um coro.

9. Já que essa configuração ocorre exclusivamente no Samba Chula, ela será detalhada mais adiante.

10. "I believe that the vitality of this music is best understood and appreciated in the context of a larger scheme of rhythmic expression which embraces just about all aspects of West African traditional life. Musical expression (or, essentially, rhythmic expression) is not divorced from other forms of communication-speech, gesture, greetings, and dance - but derives directly from these. To put it crudely but more to the point: Africans do not suddenly 'become rhythmic' on the village arena where they do their daily dance and drumming. Rather, a unitary conception informs the variety of ways in which they express themselves rhythmically, whether this be in the form of children's game songs, or lullabies, or music accompanying worship, or work songs, or songs of insult, or greeting formulas, or dance, or speech".

11. "Samba de parada refers to the fact that the singers stop (param) singing while one dancer dances, and the dancer stops dancing for the singers to sing. In the samba corrido (running samba), on the other hand, not only are the singing and the dancing continuous and simultaneous, but several dancers may enter the roda at one time, all of which is rigorously prohibited in the samba de parada".

12. Mestre Vavá (Valdefrido de Jesus), apud PINTO, 1991, p. 108.

13. Em 13 de maio de 1888, a princesa Isabel assinava a Lei Áurea, que encerrava a escravidão no Brasil. "Imperador" refere-se a seu pai, Dom Pedro II.

14. Samba do grupo "Samba de Viola", de São Félix.

15. "Weiterhin unerwartet für ein angeblich patriarchales Land ist der groé Anteil von Partnerwechseln bei den Frauen, auf der Ilha do Dendê ebenso wie in anderen vergleichbaren Siedlungen des Recôncavo".

16. Citado por Sílvio Romero (1883, p. 122-123) como proveniente do Rio Grande do Sul.

17. "Same phenomenon but call it according to different aspects".

18. Há outras classificações regionais do samba de roda, como o samba-versado, o samba-decaboclo e o samba-de-caruru. Elas parecem basear-se exclusivamente no conteúdo e forma poéticos e no contexto em que se realizam (candomblé de caboclo, caruru de São Cosme e Damião, et.), e não em diferenças musicais e performáticas.

19. "Werden ganze Einheiten wiederholt, so können innerhalb solcher Einheiten einzelne Wörter in der Wiederholung durch andere ersetzt werden, ein Name etwa oder andere Wörter, je nach Lust und Laune des Sängers oder nach den Erfordernissen der jeweiligen Situation. Nutzt man diese Technik der Substituierung richtig aus, so können alte, traditionelle Lieder eine Neufassung erhalten, um Wohltätern zu danken, um zu warnen, zu schmeicheln, zu spotten oder zu loben, wo es angebracht ist".

20. As linhas verticais da notação representam os pulsos elementares, podendo ser interpretadas como unidades de colcheia. As linhas mais grossas representam os beats, vistos como tempos fortes na teoria da música ocidental.

21. Aqui podem ter havido equívocos terminológicos. Chulo é sinônimo de grosseiro, baixo, obsceno, e pode ter sido um termo, assim como batuque, para denominar diversas danças populares. 
22. "Im Samba Chula ist [chula] der Gesang eine[r] Strophe, die aus 2 bis 4 Versen besteht, und von einem fast immer männlichen Gesangsduo (Parelha genannt) gesungen wird. Anders als im Samba Corrido wird der Vers nicht im Responsorialgesang vom Chor wiederholt oder beantwortet. Die Chula kann eine klare Aussage treffen oder auch symbolisch sein, als Metapher oder freie Poesie, deren tiefere Bedeutung in manchen Fällen schon verloren gegangen ist, bzw. nur noch von den Älteren verstanden wird. Üblicherweise wird die Chula von einem so genannten Relativo gefolgt, eine etwas kürzere Strophe, die von einem anderen Duo gesungen wird und die Chula auf eine oft lustige Weise kommentiert oder abschließt".

23. Os cantadores de chula ilustrados são respectivamente das seguintes cidades: Santiago do Iguape, São Braz e Mar Grande.

24. Modos gregorianos são comuns no nordeste do Brasil, principalmente o mixolídio e o hipolídio. Ver Padre José Geraldo de Souza, "Contribuição rítmico-modal do canto gregoriano para a música popular brasileira”. In: Revista do Arquivo 27/163, São Paulo 1959, S. 39-66.

25. "The presence of modality and parallel thirds in the „Angolan" strain of street Samba could be easily interpreted as "Portuguese". The fact is, however, that in the domain of tone systems and multi-part singing Angolan and Portuguese traits reinforced each other in Brazil. The nearequiheptatonic of inland Angola structurally linked with singing in (neutral) third-plus-fourth or third-plus-fifth chains and the diatonic tone system of Western European folk music linked with singing in major/minor parallel thirds made a perfect blend in Brazil. Yoruba music on the other hand continued in Bahia with its pentatonic system and absence of harmonic part singing".

26. 0 artigo de Rosa Maria Zamith, 1994, p. 62 e a música "Dindinha" do grupo Barravento, álbum Barravento.

27. Mário de Andrade também documentou o termo "nos sentidos de voz mais grave de uma melodia e do cantor que possui a tessitura de baixo" (1989, p. 40).

28. Na já citada gravação de Oliveira Pinto, "Embarca morena", a ponte instrumental alterna igualmente entre sétima maior e menor.

\section{RESUMOS}

"Samba" significa ao mesmo tempo festa, música e dança. No Recôncavo Baiano, Brasil, o Samba de Roda pode acontecer como uma comemoração no próprio dia-a-dia, tanto como encerramento de festividades religiosas. Este artigo apresenta aspectos musicológicos e coreográficos característicos da prática musical, interpretando-os como símbolos identitários da cultura regional. Tais dados analíticos da performance do Samba de Roda tornam-se marcas de historicidade, a serem reconhecidas em relatos históricos da cultura popular do país. Atividade cotidiana ou ritual, sambar é celebrar a identidade e a memória dos afro-brasileiros.

«Samba » signifie à la fois fête, musique et danse. Au Recôncavo de Bahia (Brésil), le samba de roda peut se présenter en outre dans la forme d'une commémoration inscrite dans la vie quotidienne ou comme l'événement de clôture d'une fête religieuse. Cet article présente certains aspects musicologiques et chorégraphiques caractéristiques de cette pratique musicale, en les interprétant comme des symboles identitaires de la culture régionale. Les données analytiques de la performance du samba de roda deviennent des marques d'historicité, reconnues dans des récits historiques de la culture populaire du pays. Activité quotidienne ou rituelle, "sambar" signifie célébrer l'identité et la mémoire des Afro-brésiliens. 
ÍNDICE

Palavras-chave: samba de roda, música e dança, identidade, cultura afro-brasileira, performance musical, marcas de historicidade

Mots-clés: samba de roda, musique et danse, identité, culture Afro-brésilienne, performance musicale, marques d'historicité

\section{AUTOR}

NINA GRAEFF

Cátedra "Transcultural Music Studies", Instituto de Musicologia Weimar-Jena/Escola Superior de Música FRANZ LISZT Weimar e Universidade Friedrich-Schiller

Jena Etnomusicologianina.graeff[at]hfm-weimar.de 